\title{
The Growing Growers Training Program: An Apprenticeship Program for Market Gardeners Serving Kansas City
}

\author{
Edward Carey ${ }^{1}$, Katherine Kelly ${ }^{2}$, Mary Hendrickson ${ }^{3}$, \\ Dan Nagengast ${ }^{4}$, James Quinn ${ }^{5}$, Craig Volland ${ }^{6}$, and Lala Kumar ${ }^{7}$
}

\begin{abstract}
ADDITIONAL INDEX WORDs. experiential learning, market farming, farmer training
Summary. The Growing Growers Training Program facilitates on-farm apprenticeships complemented by workshops on critical skills to train new growers and improve the skills of existing growers to meet large demand for local and organically grown produce in the Kansas City metropolitan area. The program is a collaborative effort of Kansas State University, University of Missouri Extension, the Kansas City Food Circle, and the Kansas Rural Center, and was established in response to requests by area organic growers for a training program to increase numbers of local organic producers. In Fall 2003, we developed the components of the program, including a curriculum designed to help apprentices gain a set of core competencies through practical and theoretical training activities, including one-on-one training by host farmers, readings, workshops and farm tours. During the 2004 growing season 11 apprentices worked part time or volunteered on eight host farms, and participated in a series of 11 workshops and farm tours. Based on self-assessment, apprentices felt they gained considerable skill in most of the core competencies. Both apprentices and host farmers expressed high satisfaction with the program. At the start of the 2005 season, demand for the program increased, with 25 apprentices with diverse backgrounds placed on 12 host farms. Workshop participation was not restricted to apprentices, and over 200 trainees paid to attend workshops during 2004, helping to generate funds to cover program costs. It is still early to judge program success, but eight of 11 of the 2004 apprentices were engaged in full- or parttime market gardening in 2005.
\end{abstract}

$\mathrm{T}$ There is large consumer demand for locally grown farm products in the Kansas City area (Burress et al., 2000). This demand is not restricted to organically grown products, but includes conventional as well, as long as the product is identified as local. Demand for local and organic farm products in the greater Kansas City metropolitan area (a six-county area

Work supported in part by grant LNC03-238 from USDA North Central Region SARE Program. Contribution \#06-259-J of the Kansas Agricultural Experiment Station.

${ }^{1}$ Department of Horticulture, Kansas State University, 35125 W. 135th St., Olathe, KS 66061. To whom reprint requests should be directed; e-mail tcarey@ksu.edu

${ }^{2}$ Kansas City Center for Urban Agriculture, P.O. Box 6043, Kansas City, KS 66106.

${ }^{3}$ Department of Rural Sociology, 201 Gentry Hall, University of Missouri, Columbia, MO 65211.

${ }^{4}$ Kansas Rural Center, P.O. Box 133, Whiting, KS 66552.

${ }^{5}$ Department of Horticulture, 1-87 Agriculture Building, University of Missouri, Columbia, MO 65211.

${ }^{6}$ Kansas City Food Circle, P.O. Box 45195, Kansas City, MO 64171.

${ }^{7}$ University of Missouri Extension, 1501 NW Jefferson, Suite 110, Blue Springs, MO 64015. comprising Kansas City, Kans.; Kansas City, Mo.; and numerous additional municipalities, with a total population of about 2 million), is reflected in numbers of startup and existing farmers markets, and in frequent articles in area newspapers extolling the virtues of fresh, local farm products. This demand has been estimated at $\$ 100$ million annually (D. Burress, personal communication), but only a small fraction of that demand is met, even at the height of the summer production season.

We established our apprenticeship program, the Growing Growers Training Program (Growing Growers), to train new, primarily organic growers, in the Kansas City food shed (roughly defined as locations within a 100-mile radius of Kansas City), and to improve skills of existing growers. Farming is a profession that requires multiple skills related to production, marketing, and financial management. New farmers need to learn these sets of skills as they enter the field, while established farmers constantly work to improve skills to respond to changing circumstances and new information about sustainable farming practices.

In establishing our program, we drew upon a number of existing resources and programs that train new growers with an emphasis on organic and sustainable methods and typically, on direct market sales. Key among these was the Upper Midwest Collaborative Regional Alliance for Farmer Training (CRAFT) (CSA Learning Center (a) Angelic Organics, 2006), one of a number of programs organized by biodynamic and organic farmers and market gardeners to strengthen the training experience of farm interns. This program identified core competencies for beginning farmers to be developed through a program of workshops, farm events, intern exchanges and workshops (Mandt, 2002). Additional sources of information on internship programs and farmer training were the Northeast Organic Farming Association of New York (Jones, 1999); Maine Organic Farming and Gardening Association's (2004) apprenticeship program; Wisconsin School for Beginning Market Growers of the University of Wisconsin Center for Integrated Agricultural Systems (2004), an intensive short-course on major aspects of diversified vegetable production and marketing, which is taught by grower-instructors, complemented by extension specialists; and the Farm and Garden Apprenticeship Program of the University of California Santa Cruz Center for Agroecology and Sustainable Food Systems (Miles and Brown, 2003, 2005). The Land Stewardship Project (2001) runs a "Farm Beginnings" program based on coursework and mentoring by farmers aimed at assisting new farmers to begin profitable family farms in a number of states.

Growing Growers builds on and pulls together existing extension and outreach efforts by various partners, including Kansas State University Research and Extension and the University of Missouri Extension, which aim at improving farmers' skills and strengthening local and regional food systems. The University of Missouri Food Circles Networking Project (2003) has a major goal of strengthening local food systems in Missouri, and has worked in the Kansas City area to establish farmers markets, and strengthen linkages between restau- 
rants and growers, among other things. The Kansas City Food Circle (2006) is a volunteer alliance of consumers and producers that works to strengthen ties between local producers and consumers. It publishes a directory of local food producers, and runs an annual farmers exhibition. The Kansas Rural Center (2004) has been active in efforts to strengthen local food systems and to serve farmers in Kansas. The Kansas City Center for Urban Agriculture (2006) is dedicated to the support and promotion of urban agriculture. The Great Plains Vegetable Growers Conference and the Mid-America Fruit Growers Conference are noteworthy cooperative regional efforts by extension and grower organizations that are relevant to strengthening grower skills for local production and marketing in
Kansas City. Representatives of partner organizations serve on the advisory board of the Growing Growers.

\section{Program development}

At the outset, we developed a set of core competencies by asking a few organic direct market farmers to list topic areas and skill sets that they felt are essential for successful farmers. Sixty-eight specific areas of competency were identified in the following 15 general areas: soils, crops, pests, diseases, weeds, weather, harvest and postharvest, production planning, equipment, land, farm design, marketing, farm business management, eating, and integrating livestock into the market farm. Each area of competency was assigned a high, medium, or low priority for first-year apprentice training.
Competencies for two of these areas, soils and marketing, are presented in Table 1 along with preferred training method(s) for gaining competence in each area. These include hands-on training, one-on-one sessions with the host farmer, workshops, readings, and apprentice-directed independent study. Hands-on training includes all aspects of crop production on the farm, and exposure to marketing. One-on-one (farmer-directed training) by the host farmers is an important part of the program. Over the course of the season, host farmers are paid to provide 12 to $15 \mathrm{~h}$ of training on specific topics that cannot be covered through hands-on training. Topics covered may include soil building, rotations, production planning, seed selection and ordering, equipment operation, organic certifica-

Table 1. Core competencies in two subject matter areas, priorities and training modalities for first-year apprentices in the Growing Growers Training Program in 2004 and 2005. Pre- and post-season self-assessments by 2004 class of apprentices also are given. ${ }^{\mathrm{z}}$

\begin{tabular}{|c|c|c|c|c|c|c|c|c|c|}
\hline \multirow[b]{2}{*}{ Area } & \multirow[b]{2}{*}{ Specific topics } & \multirow[b]{2}{*}{ Priority } & \multirow[b]{2}{*}{$\begin{array}{c}\text { Hands- } \\
\text { on }\end{array}$} & \multirow[b]{2}{*}{$\begin{array}{l}\text { One-on- } \\
\text { one }\end{array}$} & \multirow[b]{2}{*}{$\begin{array}{l}\text { Work- } \\
\text { shops }\end{array}$} & \multirow[b]{2}{*}{$\begin{array}{l}\text { Written } \\
\text { resources }\end{array}$} & \multirow[b]{2}{*}{$\begin{array}{l}\text { Apprentice } \\
\text { directed }\end{array}$} & \multicolumn{2}{|c|}{$\begin{array}{c}\text { Apprentice } \\
\text { self-assessment } \\
(1-10 \text { scale })^{y}\end{array}$} \\
\hline & & & & & & & & $\begin{array}{c}\text { Pre- } \\
\text { season }\end{array}$ & $\begin{array}{l}\text { Post- } \\
\text { season }\end{array}$ \\
\hline \multirow[t]{4}{*}{ Soils } & $\begin{array}{l}\text { Basic overview of } \\
\text { types, fertility, microbiology }\end{array}$ & High & & & $\mathrm{X}$ & $\mathrm{X}$ & & 3.8 & 7.0 \\
\hline & $\begin{array}{l}\text { Practical considerations: recognizing } \\
\text { moisture and soil conditions, tillage, tilth, etc. }\end{array}$ & High & $\mathrm{X}$ & & & & & 3.6 & 9.3 \\
\hline & Composting and compost teas & Med & $\mathrm{X}$ & & $\mathrm{X}$ & & & 4.6 & 7.9 \\
\hline & Identifying and controlling erosion & Med & $\mathrm{X}$ & & & & & 5.0 & 7.7 \\
\hline \multirow{8}{*}{ Marketing } & $\begin{array}{l}\text { Selecting your products: vegetables, fruit, } \\
\text { dairy, meat, etc. }\end{array}$ & High & $\mathrm{X}$ & $\mathrm{X}$ & & & $\mathrm{X}$ & 4.0 & 8.6 \\
\hline & Presenting your product for maximum sales & High & $\mathrm{X}$ & & $\mathrm{X}$ & & & 4.4 & 8.3 \\
\hline & Knowing, explaining and selling your product & High & $\mathrm{X}$ & & $\mathrm{X}$ & & & 4.5 & 9.0 \\
\hline & $\begin{array}{l}\text { Consumer education on health and nutrition } \\
\text { and how to cook with your product }\end{array}$ & Med & $\mathrm{X}$ & & $\mathrm{X}$ & & & 6.3 & 9.1 \\
\hline & Advertising and media & High & & & $\mathrm{X}$ & & & 4.0 & 7.6 \\
\hline & $\begin{array}{l}\text { Marketing tools, supplies and guidelines: . } \\
\text { packaging, invoicing, record-keeping, etc }\end{array}$ & High & $\mathrm{X}$ & $\mathrm{X}$ & $\mathrm{X}$ & & & 4.1 & 7.3 \\
\hline & Pricing & High & $\mathrm{X}$ & & $\mathrm{X}$ & & $\mathrm{X}$ & 3.4 & 7.3 \\
\hline & $\begin{array}{l}\text { Consumer psychology, building and } \\
\text { maintaining relationships }\end{array}$ & High & $\mathrm{X}$ & & $\mathrm{X}$ & & & 4.6 & 8.3 \\
\hline
\end{tabular}

${ }^{2}$ Core competencies are the general skills, knowledge, and experiences that we consider to be useful to a farmer growing food for local consumption. They are prioritized as high, medium, and low to reflect what we thought would be possible to cover in a one-season apprenticeship. Items rated "high" are addressed during the apprenticeship year. Items rated as "medium" were introduced during the year; items rated as low were not directly addressed. The complete set of core competencies can be found on the Growing Growers Training Program website (2004b).

y Apprentice self-assessments used a 1 to 10 scale, where 1 indicates no competence and 10 indicates full competence. The list continues to be revised and refined. For preassessment, $\mathrm{n}=8$, and for post-assessment, $\mathrm{n}=7$.

${ }^{\mathrm{x}}$ CSAs are farms using the community supported agriculture system of marketing. 
tion, market planning, budgets, etc., and typically involve detailed reference to farm records. Apprentice-directed training (research and discussion) is also envisaged, where apprentices are responsible for "interviewing" their farmers on particular topics and then sharing and discussing the information with the other apprentices. Farm exchanges of up to 1 week were envisaged to allow apprentices to gain additional experience from working on other farms. The complete set of competencies can be found on the Growing Growers website (Growing Growers, 2004b) and is subject to revision on an ongoing basis.

Monthly workshops cover a range of topics during the course of the growing season and typically involve both formal presentations by subject matter specialists and presentations by experienced growers, complemented by farm tours. Workshops held in 2004 covered the following areas: soils; plant production; integrating animals into the vegetable farm; farm safety; taste; pests, diseases, and weeds; postharvest handling; equipment; and business planning. Apprentices are required to attend monthly workshops, which are programmed to avoid conflict with farm labor requirements (typically
Monday afternoons during the farmers' market season, and all day outside of the main growing season). In addition to regular monthly workshops, Growing Growers offers occasional advanced or introductory workshops designed to serve a broader audience in the Kansas City food shed, or to generate interest in market farming as a profession. Table 2 provides a sample of workshops conducted in 2003 and 2004. The complete list of workshops is posted on the Growing Growers website (Growing Growers, 2004a).

Written resources are also provided to apprentices. The list, which is subject to ongoing revision, includes a number of textbooks complemented by various extension bulletins. Core texts include Coleman (1995) and Grubinger (1999). A complete list of written resources is posted on the Growing Growers website (Growing Growers, 2004c).

Growing Growers is run by a program manager and director in consultation with an advisory board made up of representatives of the partner organizations and growers. Initial steps in establishing the program involved developing procedures for application for apprentices and host farms, and publicizing the program in order to generate interest. A website was developed where information, including application forms and procedures, for apprentices and host farmers is posted. A listserve was set up to serve the grower community in the Kansas City food shed. We listed the apprenticeship program on websites listing farm internships nationally. To join the program, host farms apply for admission, describing their operations and committing to provide training to one or more apprentices over the course of the season. While being organic is not a prerequisite for being a host farm-evidence of sustainable practices is the minimum requirement-most host farms are either certified organic or use organic practices. Host farm descriptions and contact information are posted on the website. Would-be apprentices submit applications to the program, and are then asked by the program manager to contact host farmers to attempt to identify a host farm. Host farmers are encouraged to do a thorough job of interviewing potential apprentices to help ensure the success of the training. Following agreement by host farmers and apprentices, proposed lists of apprentices and their host farms are presented to the advisory board for approval. Initially we anticipated that

Table 2. Examples of workshops for organic and sustainable market gardeners offered by the Growing Growers Training Program to apprentices and a wider audience of growers and would-be growers during 2003 to $2004^{\mathrm{z}}$.

\begin{tabular}{|c|c|c|c|c|c|}
\hline Workshop title & Description & Venue & Date & Type $^{y}$ & Attendance \\
\hline $\begin{array}{l}\text { Tools for dealing } \\
\text { with drought: Mulches, } \\
\text { irrigation, soil building } \\
\text { and high tunnels for the } \\
\text { market gardener }\end{array}$ & $\begin{array}{l}\text { All-day program. Lectures } \\
\text { by extension specialists, } \\
\text { field tour and equipment } \\
\text { demonstration. }\end{array}$ & $\begin{array}{l}\text { Kansas State University } \\
\text { Research and Extension } \\
\text { Center, Olathe, Kans. }\end{array}$ & Nov. 2003 & Advanced & 70 \\
\hline $\begin{array}{l}\text { So you want to be a } \\
\text { market gardener- } \\
\text { getting started in a } \\
\text { noble profession }\end{array}$ & $\begin{array}{l}\text { All-day program. Overview } \\
\text { lecture on market farming; } \\
\text { grower panels on "my life as a } \\
\text { farmer" and "scale and focus." }\end{array}$ & $\begin{array}{l}\text { Great Plains Vegetable } \\
\text { Growers Conference, } \\
\text { St. Joseph, Mo. }\end{array}$ & Jan. 2004 & Introductory & $20-45$ \\
\hline $\begin{array}{l}\text { Soil building for the } \\
\text { vegetable and fruit } \\
\text { grower }\end{array}$ & $\begin{array}{l}\text { All-day program. Lectures } \\
\text { by extension specialists and } \\
\text { growers on soil quality, } \\
\text { fertilization, biology, compost, } \\
\text { and cover crops, and farm tour }\end{array}$ & Leavenworth, Kans. & Mar. 2004 & Regular & 42 \\
\hline Pests, diseases and weeds & $\begin{array}{l}\text { All day program. Lectures by } \\
\text { extension specialists (pests, } \\
\text { diseases) and grower educator } \\
\text { (weeds), including farm visit. }\end{array}$ & $\begin{array}{l}\text { Drumm Farm, } \\
\text { Independence, Mo. }\end{array}$ & Aug. 2004 & Regular & 25 \\
\hline
\end{tabular}

${ }^{2}$ Monthly workshops were conducted during the growing season; introductory workshops were conducted once per year at the regional vegetable growers conference; advanced workshops were held occasionally. A complete listing of workshops held by year can be found on the Growing Growers Training Program website (2004a).

yAll workshops were open to a general audience of growers and would-be growers for a fee. Apprentices were required to attend regular workshops. 
all apprentices would be paid, fulltime employees, but it soon became clear that some of the potential host farms could not afford to pay full-time employees. We therefore allowed for either paid apprentices (minimum of $20 \mathrm{~h}$ perweek) or volunteer apprentices (minimum of $4 \mathrm{~h}$ per week).

\section{Program results}

In 2004 and 2005, most host farms and apprentices who applied were accepted into the program. In 2004, 12 apprentices ( 10 paid and two volunteer) were placed on eight farms, and in 2005 a total of 28 apprentices (14 paid and 14 volunteer) were placed on 14 farms. Eleven of the 12 apprentices that started in 2004 completed the program successfully, attending at least $80 \%$ of workshops, and 19 out of 28 completed the program in 2005. At the beginning of the season, apprentices were required to attend an orientation session where they were asked to assess their level of competence for each of the core competencies. This exercise was repeated at the end of the season. Pre- and post-season self-assessment by the 2004 apprentices for selected core competencies are presented in Table l. The increases in self-assessment indicate an increased confidence on the part of graduates in their understanding of all of the core competencies, even in cases where the topic was not dealt with through training. Of the 2004 class of apprentices who completed the program, eight were involved in market farming or related enterprises (one apprentice opened a restaurant showcasing local farm products) in 2005. Apprentices in both years were of diverse backgrounds, ages, and economic status, ranging from inner city youths to professionals interested in a career change. Some owned farms already and were looking for the skills to farm profitably. In 2005 all but three apprentices were women.

At the end of the 2004 season, both apprentices and host farmers expressed high satisfaction with the program. High host farmer retention and increased apprentice enrollment in 2005 were reflective of this satisfaction. While satisfied with the program, apprentices did identify areas for improvement, including a desire for emerging from the program with a greater sense of community with other apprentices, and a wish that they could have taken part in farm exchanges. Apprentices were responsible for organizing farm exchanges, and these did not take place either year, possibly because this is an optional aspect of the program, and difficult to organize during the height of the growing season. In order to improve communication among apprentices, we intend to conduct future apprentice orientation meetings in a retreat setting so as to provide time to get to know each other in a social setting and to plan for possible farm exchanges and other communication later in the season.

Host farmers were also happy with Growing Growers. Several host farmers reported that having apprentices improved their farm operation in some way, including increased production, or changed practices as a result of the need for self-assessment as part of the teaching process. Host farmers also developed and improved skills as farmer trainers, both through one-on-one training of apprentices, and in some cases by serving as trainers in workshops or during farm tours associated with workshops. Most of the host farms are relatively small, direct market operations, and we are somewhat concerned that apprenticeships on those farms will lead to self-replication of similar supplemental income operations. The training program thus will continue to strive to include larger-scale operations as host farms as they develop in the Kansas City food shed, and as examples in workshops and farm tours. Some host farmers and apprentices were interested in continuing their apprenticeships, so we are in the process of developing a second-year apprenticeship program that will provide an opportunity for continuing training, with higher levels of responsibility and skill development required of apprentices in specific areas.

\section{Program support and sustainability}

The program was initiated in 2003 with support from a U.S. Department of Agriculture, Sustainable Agriculture Research and Education (SARE) grant. A second SARE grant will continue to provide decreasing levels of support to the program through 2007, as we seek to make the program self-sustaining. To date, workshop registrations and book sales to non-apprentices have generated some operating income, but not sufficient to cover management costs. Program services, including all workshops and training materials, have been free to apprentices. We plan to move toward a fee-based program to cover costs for those who can afford to pay, complemented by scholarships for those unable to pay. Depending on continued demand for the program, management costs may be increasingly assumed by Kansas State University and University of Missouri extension and sustainable agriculture programs. We will explore opportunities for apprentices to receive credit through undergraduate internships and continuing education programs. In addition to funds that may be generated through tuition payments, we will seek ongoing assistance for scholarships from area foundations and businesses, such as produce distributors, farm and garden suppliers, and that will benefit from increased supply of locally grown organic produce.

\section{Conclusions}

The Growing Growers Training Program appears to be off to a strong start, providing apprenticeships and workshops to train new market farmers and improve the skills of existing farmers serving the Kansas City with organic and sustainably produced farm products. Critical challenges lie ahead with respect to maintaining and improving the program. Nevertheless, the high visibility of the program, attained through frequent workshops throughout the growing season, appears to be serving an important extension function and is garnering support both within our university extension systems, and in a wider population of regional producers and users of local farm products.

\section{Literature cited}

Burress, D., B. Harris, and P. Oslund. 2000. Kaw Valley demands for local and organic product: Surveys and models. Proc. IFOAM 2000: The world grows organic, 13th Intl. Sci. Conf., Intl. Federation of Organic Agr. Movements, Basel, Switzerland. p. 537-540.

Coleman, E. 1995. The new organic grower. Chelsea Green, White River Junction, Vt.

CSA Learning Center@ Angelic Organics. 2006. CRAFT farmer training opportunities. 8 Mar. 2006. <http://www.csalearningcenter.org/craft.html>.

Growing Growers Training Program. 2004a. Growing Growers Training Pro- 
gram-2003 and 2004 workshops. 9 Mar. 2006. <http://www.growinggrowers. org/documents/2004workshops.pdf>.

Growing Growers Training Program. 2004b. Growing Growers Training Program-Core competencies. 8 Mar. 2006. <http://www.growinggrowers.org/documents/competencies.pdf>.

Growing Growers Training Program. 2004c. Growing Growers Training Program-Text resources for apprentices. 8 Mar. 2006. <http://www.growinggrowers.org/documents/textresources.pdf>.

Grubinger, V.P. 1999. Sustainable vegetable production from start-up to market. NRAES-104. Natural Resource, Agr. and Eng. Serv., Ithaca, N.Y.

Jones, D. 1999. Internships in sustainable farming: A handbook for farmers. $21 \mathrm{Jan}$. 2006. <http://nofany.org/images/publications/internshiphandbook.pdf>.

Kansas City Center for Urban Agriculture. 2006. Kansas City Ctr. for Urban Agr. 8 Mar. 2006. <http://www.kccua.org>.

Kansas City Food Circle. 2006. Kansas City Food Circle. 8 Mar. 2006. <http:// kcfoodcircle.org $>$.

Kansas Rural Center. 2004. Kansas Rural Center. 8 Mar. 2006. <http://www.kansasruralcenter.org>.

Land Stewardship Project. 2001. Farm beginnings. 8 Mar. 2006. <http://www. landstewardshipproject.org/programs_ farmbeginnings.html>.

Maine Organic Farming and Gardening Association. 2004. MOFGA's apprenticeship program. 8 Mar. 2006. <http://www. mofga.org/apprinfo_04.html>.

Mandt, J. 2002. 2002 Handbook: Upper Midwest CRAFT region I-Southern Wisconsin \& northern Illinois. CSA Learning Ctr. @ Angelic Organics, Caledonia, Ill.

Miles, A. and M. Brown. 2003. Teaching organic farming and gardening: Resources for instructors. 21 Jan. 2006. <http:// zzyx.ucsc.edu/casfs/instruction/tofg/ contents.html>.

Miles, A. and M. Brown. 2005. Teaching direct marketing and small farm viability: Resources for instructors. 21 Jan. 2006. <http://zzyx.ucsc.edu/casfs/instruction/tdm/contents.html>.

University of Missouri. 2003. Food Circles Networking Project. 8 Mar. 2006. <http:// www.foodcircles.missouri.edu/>.

University of Wisconsin Center for Integrated Agricultural Systems. 2004. Wisconsin school for beginning market growers. 8 Mar. 2006. <http://www.cias. wisc.edu/marketgrower.php>. 